\title{
CONHECIMENTO CIENTÍFICO, MÚSICA E ARTE TRÁGICA**
}

\author{
José Fernandes Weber ${ }^{*}$
}

\begin{abstract}
RESUMO
O artigo explora tanto os pressupostos quanto as implicações da "morte trágica da tragédia grega", tal qual aparece desenvolvida na obra $O$ Nascimento da Tragédia de Nietzsche. Explorando a contraposição entre conhecimento científico e arte trágica busca-se mostrar o quanto a interpretação nietzscheana da Grécia está marcada por problemas que vinculam-na à tradição estético-filosófica da Alemanha do final do século XVIII e do século XIX. Será a obra de Wagner que funcionará como a ponte entre os "dois mundos" (Grécia e Alemanha), pois é através da música wagneriana, em que o espírito da tragédia se faz presente, que o limite da visão científica de mundo se fará ver com mais clareza e intensidade e em que se vislumbrará o retorno do trágico.
\end{abstract}

PALAVRAS-CHAVE: Nietzsche. Conhecimento científico. Música. Arte trágica.

\footnotetext{
* Doutor em educação pela UNICAMP e professor titular do Departamento de Filosofia da Universidade Estadual de Londrina (UEL). Email: jweber@uel.br.

** O presente artigo beneficiou-se de uma bolsa (concedida pela Capes) de "Estágio de Doutorando no Exterior", realizado entre maio de 2004 e fevereiro de 2005 junto a Universidade Nova de Lisboa (Portugal). Também resulta do Projeto de Pesquisa "Bildung (Formação, Cultivo) e Modernidade: entre Filosofia, Educação e Artes", financiado pela Fundação Araucária (Paraná).
} 


\begin{abstract}
The article deals both with the presuppositions and the implications of the "tragic death of the Greek tragedy", the way it is developed in the work The Birth of Tragedy by Nietzsche. Exploring the counterposition between scientific knowledge and tragic art it is intended to show how the nietzschean interpretation of Greece is marked by problem that link it to the German aesthetic-philosophical tradition of the end of the $18^{\text {th }}$ century and the $19^{\text {th }}$ century. Wagner's work will act as the bridge between "both worlds" (Greece and Germany), for it is through Wagnerian music in which the spirit of tragedy is present, that the boundary of the scientific view of the world will be seen more clearly and intensely and that it will be possible to conjecture the return of the tragic.
\end{abstract}

KEYWORDS: Nietzsche. Scientific knowledge. Music. Tragic art.

"Quero falar apenas da oposição mais ilustre à consideração trágica do mundo, e com isso me refiro à ciência, otimista em sua essência mais profunda, com o seu progenitor Sócrates à testa." (NIETZSCHE, 1992b, p. 97)

Tragicamente morreu a tragédia grega! Este parece ser o fato evidente, embora pouco percebido, ainda menos "divulgado" pelos filólogos e laboriosos amantes da Grécia, alemães que Nietzsche faz ecoar em sua obra $O$ Nascimento da Tragédia. ${ }^{1}$ Então, evidente, mas mascarado. Por qual motivo? A primeira obra publicada por Nietzsche pretende ser um inventário, tanto das razões do desaparecimento da tragédia quanto do ocultamento deste fato. E assim, não deveria causar embaraço e espanto se, seguindo Nietzsche, ao adentrarmos no labirinto do mundo grego, nos deparássemos com figuras cativas

\footnotetext{
${ }^{1}$ Doravante NT.

Educ. e Filos. Uberlândia, v. 23, n 45, p. 47-64, jan./jun. 2009. 
modernas, afinal, tanto em nossa constituição quanto em nossas defasagens continuamos topando com os gregos. ${ }^{2}$

A tragédia grega desapareceu num curto espaço de tempo: do seu aparecimento até a sua completa dissolução, distam cem anos. Diferentemente das outras formas de arte que desfrutaram de uma "serena velhice", a tragédia morreu tragicamente, não deixando rebentos ou um tipo de arte que a sucedesse à altura. De acordo com Nietzsche, a dissolução da arte trágica não estava relacionada apenas com uma mudança da estrutura cênica, logo, não dizia respeito apenas ao domínio interno das técnicas da arte, sendo resultado de um movimento mais abrangente de transformação do próprio "gosto" grego. Posto que a Grécia arcaica constituía uma cultura artística, tal mudança resultou de uma transformação da vivência dos impulsos. Em suma, teriam os gregos recusado a vivência dos seus impulsos artísticos em favor de uma consideração científica da existência?

A reflexão nietzscheana sobre a morte da tragédia incita à consideração da relação entre o palco grego, a platéia e a polis. Em $O$ drama musical grego, texto da palestra proferida em 1870 na Universidade da Basiléia, Nietzsche afirmou que "Algo desta vida natural dionisíaca também estava presente na alma dos espectadores no tempo do florescimento do drama ático" (NIETZSCHE, 1988, p. 522). A excelência da arte trágica consistiu na simbiose perfeita entre os temas, a forma e o conteúdo da peça, com os impulsos da multidão dos espectadores. E o mais importante: a tragédia enquanto espetáculo e culto ao deus Dionísio instituiu-se em festejo e celebração públicos na polis, graças a profunda afinidade com o dionisíaco, afinal, de acordo com Nietzsche, o dionisíaco habitava a alma dos espectadores.

Com Eurípedes e Sócrates ocorreu algo de irremediável: a tensão na peça, característica da disposição dionisíaca, esvaiu-se em

\footnotetext{
${ }^{2}$ A este propósito, ver a "Tentativa de Autocrítica" a $O$ nascimento da Tragédia, publicado em 1886 por ocasião da nova edição da obra em que Nietzsche afirma ter estragado o problema grego com questões modernas, alemãs.
} 
favor da clarividência, própria aos procedimentos dialéticos, dos quais, aqueles foram os grandes arautos. Conforme já apresentado, o prólogo euripidiano representou a incorporação do princípio socrático "tudo deve ser consciente para ser bom" no domínio da cena, transmutando-se em Eurípedes no mote estético: "tudo deve ser consciente para ser belo". "Em conseqüência disso, diz Nietzsche, Eurípedes deve valer para nós como o poeta do socratismo estético" (NIETZSCHE, 1992b, p. 83).

Algumas passagens de NT podem despertar uma certa "curiosidade documental". Nelas se afirma que Sócrates auxiliava Eurípedes em seu poetar, ou ainda, que Sócrates não assistia às representações trágicas, exceto quando uma nova peça de Eurípedes era apresentada. Independentemente da justeza documental, o mais importante é perceber as questões suscitadas por estas afirmações. Se há em Eurípedes e Sócrates um procedimento comum que culmina com a morte da tragédia, trata-se então de investigar a relação deste procedimento com a recepção da nova arte por parte do espectador e não averiguar a ingerência (direta) de Sócrates sobre a criação poética euripideana. Afinal, os casos de Eurípedes e de Sócrates não representavam uma exceção.

Segundo Nietzsche, a partir de Sócrates, a cultura grega em seu conjunto decaiu, sendo a filosofia platônica a expressão mais bem sucedida deste movimento decadencial. Em outras palavras, a filosofia foi o fruto de uma cultura decadente! A decadência da cultura grega, diagnosticada por Nietzsche na destruição da obra de arte trágica e, conseqüentmente, do sentimento trágico, efetivouse por intermédio da oposição entre razão e impulso (instinto), ${ }^{3}$

\footnotetext{
${ }^{3}$ Em NT Nietzsche opera com a distinção entre Instinct e Trieb. Instinct, traduzido por instinto, possui um sentido biológico e Trieb traduzido por impulso, pulsão, diz respeito às manifestações do desejo já sujeitas às influências da cultura. Em ambos os casos é notória a contraposição à razão. A este respeito ver nota 21 , p. 216-220 da tradução da obra Além do bem e do mal feita por Paulo César de Souza.
}

Educ. e Filos. Uberlândia, v. 23, n 45, p. 47-64, jan./jun. 2009. 
procedimento característico daquilo que Nietzsche nomeou como consideração científica de mundo.

$\mathrm{Na}$ Tentativa de auto-crítica de 1886, Nietzsche deu a entender que a grande questão colocada às claras em NT [...] foi o problema da ciência mesma - a ciência entendida pela primeira vez como problemática, como questionável." (NIETZSCHE, 1992b, p. 14-15). Porém, como situar a suposta problematicidade da ciência no contexto da investigação do nascimento da tragédia? Em que medida se está autorizado a falar em ciência na Grécia do século V a.C.? Em suma, não seria este um exemplo típico da projeção de um problema alheio aos gregos, projetado a partir do século XIX, que tem na reflexão sobre a ciência uma das questões mais recorrentes? ${ }^{4}$ Esta aparente inflexão na ordem das questões de NT revela que nesta obra a teoria estética não se encontra circunscrita ao âmbito dos objetos de arte, abrangendo um campo maior de significação que diz respeito a totalidade das criações humanas. A teoria estética é, sobretudo, uma teoria da cultura, na medida em que aquilo que se encontra em questão é a própria potência criadora no homem, por cujo intermédio, forja-se o exercício constante e infindável da construção do sentido para a vida, do qual resultará a cultura. Com o advento da consideração científica de mundo, esta dimensão trágicocriativa da cultura grega vem abaixo, pois o otimismo científico sacrifica a vivência trágica à clarividência do conceito.

Quando fala em ciência, Nietzsche não se refere apenas a esta

\footnotetext{
${ }^{4}$ Embora estas questões possam parecer ociosas na medida em que Nietzsche emprega, neste registro, Ciência como sinônimo de conhecimento racional, o que tornaria desnecessária a própria formulação daquelas questões, ainda assim, há uma boa razão para mantê-las, a saber: se não se trata de manter um suposto "sentido originário" da Grécia que a inflexão dos temas associados à reflexão sobre a ciência do século XIX viria macular, trata-se, porém, por via negativa, mostrar aquilo que claramente os gregos não concebiam como ciência. Se em ambos casos é comum a referência ao conhecimento racional há, porém, um abismo que separa aquelas concepções, razão suficiente para a elaboração da pergunta.
} 
forma de conhecimento cujo responsável é um técnico: o cientista. Para ele, ciência é sinônimo de consideração racional de mundo, signo de conhecimento a todo custo, do qual a ocupação científica no sentido estrito será apenas uma transmutação e um aprofundamento. A este respeito, afirma: "[...] entendo por espírito da ciência aquela crença, surgida à luz pela primeira vez na pessoa de Sócrates, na sondabilidade da natureza e na força terápica universal do saber." (NIETZSCHE, $1992 b$, p. 104). O procedimento próprio ao espírito científico sustentase numa decidida recusa da permanência de espaços ou dimensões da existência não sujeitas ao conhecimento. Ao instaurar a crença na sondabilidade da natureza, Sócrates instaurou ao mesmo tempo, a crença na cognoscibilidade completa da natureza bem como a crença na excelência desta ocupação. A conseqüência deste procedimento é a demarcação de um linha divisória bastante precisa que diz respeito aos graus de cognoscibilidade das coisas e sua relação com o grau de necessidade lógica do conhecido: quanto mais necessário ao conhecimento - entenda-se: quanto mais clarividente - mais excelente. Ora, por constituir-se como experiência de desestabilização e de afecção por forças ocultas que sobrepassam a capacidade cognoscente do homem, a tragédia representava a Sócrates um experiência abjeta. Para ele, também a arte deveria seguir os procedimentos racionais, representando assim o princípio necessário de clarividência inscrito na natureza do conhecimento, conseqüentemente, na natureza humana. Em suma, se a arte por si não é detestável, o que se torna objeto de desprezo na arte trágica anterior a Eurípedes, é a sua completa falta de lógica, a sua afecção por forças incognoscíveis e irrefreáveis. Ou seja, a sua anuência aos impulsos e aos instintos. A este respeito, em Ecce Homo, Nietzsche dirá que a oposição instaurada por Sócrates é da ordem da "racionalidade contra instinto" (NIETZSCHE, 1995, p. 62).

Porém, em Sócrates, a crença na sondabilidade da natureza, complementa-se na crença da força terapêutica do saber. $\mathrm{O}$ conhecimento é o mais desejável, por que além de permitir a delimitação, a medição, a dissecação, o esquartejamento, enfim, a 
clarificação completa de todas as interrogações, permite também e este é o seu maior valor - a recriação das condições necessárias para a estabilização daqueles elementos que de alguma maneira, afundaram numa anarquia desestabilizante. ${ }^{5} \mathrm{O}$ poder de corrigir o ser, atribuído por Sócrates ao conhecimento racional, ocupará a função de ordenação das ações a partir de um postulado prático que segue as relações causais do conhecimento lógico, dispostas no discurso segundo os postulados do diálogo. Daí decorre que a atividade investigativa é essencialmente otimista pois, se a natureza e a existência comportam intervenção, elas podem ser curadas das suas afecções através do uso das fórmulas terapêuticas que seguindo um critério lógico, corrigem as eventuais inconsistências ou contradições no ente.

$\mathrm{Na}$ avaliação de Nietzsche, a conseqüência mais funesta decorrente da consideração científica de mundo, também chamada racionalismo socrático, foi a destruição do espírito da música. Ao operar com o pressuposto da clarividência racional, Sócrates destruiu o solo mais profundo e elementar de cultivo dos costumes do povo, seio para a gestação e o desenvolvimento do mito. Esta dimensão constitutiva da saúde de uma cultura expressa na atividade estética por excelência, a música, ao vir abaixo, trouxe junto consigo toda a possibilidade de criar uma cultura estética. Restou então, um mito arremedado, signo de uma cultura arremedada. A este respeito o final do $\$ 10$ de NT é decisivo: ${ }^{6}$ "[...] E assim como o mito morreu para ti, também morreu para ti o gênio da música: e mesmo se saqueaste com presas ávidas todos os jardins da música, ainda assim só pudeste chegar a uma arremedada música mascarada" (NIETZSCHE, 1992b, p. 72).

Segundo Nietzsche, aqueles dois aspectos da crença socrática no conhecimento, constituíram os postulados fundantes de todo o

\footnotetext{
${ }^{5}$ Após o esquartejamento, há que se ministrar a Pharmakón.

${ }^{6}$ Embora se refira a Eurípedes, a citação serve de ilustração ao procedimento socrático, visto que se trata do mesmo problema: destruição do espírito da música.
} 
culto à razão no Ocidente. Neste sentido Sócrates é caracterizado por Nietzsche como "[...] um ponto de inflexão e um vértice da assim chamada história universal"(NIETZSCHE, 1992b, p. 94). Sendo assim, a oposição entre trágico e científico, instituída com Eurípedes e Sócrates, sobrepassa os limites territoriais e temporais da Grécia do século VI e V a.C. Torna-se então compreensível que, para Nietzsche, aquela oposição não figure apenas como critério de reflexão da cultura grega, mas também, como critério de reflexão e julgamento de toda a cultura ocidental, na medida em que, esta se nutriu das "lições de Eurípedes, de Sócrates e de Platão", instituindose em continuidade transmutada e intensificada dos pressupostos do espírito científico.

Se Nietzsche apresenta em NT uma decidida recusa à prevalência desta dicotomia, é por que reconhece seus efeitos nefastos. Neste período, grande parte dos seus esforços estavam voltados para a tentativa do estabelecimento de uma reflexão que congregasse para além do diagnóstico da decadência, um procedimento criador de alternativas para a superação da dicotomia arte / ciência. Ao debruçar-se sobre o difícil tema do renascimento do mito alemão, eram estes os problemas que ele tinha em mente. Neste sentido, o drama musical wagneriano, bem como a elaboração da concepção do conhecimento trágico, do filósofo do conhecimento trágico, representarão a tentativa de superação da dicotomia entre trágico e científico, pois a partir da união do artista e do filósofo, Nietzsche acreditava ser possível o ressurgimento do mito trágico. De que forma dar-se-ia tal ressurgimento? É este o problema que passaremos a considerar.

Nos seus primeiros escritos, Nietzsche denunciou que ao renunciar ao mito, os gregos renunciaram à vivência trágica pois a supremacia da tendência científica resultou na morte da tragédia. No seu entender, com a instauração desta tendência "[...] o heleno havia renunciado à crença em sua própria imortalidade, não só à crença em um passado ideal, como à crença em um futuro ideal" (NIETZSCHE, 
1992b, p. 74). Esta denúncia, base para a sua reflexão sobre a cultura grega, também serviu-lhe de sustentáculo à reflexão sobre a cultura alemã, na medida em que trouxe à tona o problema da relação entre mito e cultura.

Segundo Jürgen Habermas, Nietzsche situa-se no desdobramento de um movimento iniciado pelos autores dos movimentos literários Sturm und Drang e do romantismo alemão - principalmente, Friedrich Schlegel e o filósofo Friedrich von Schelling que fazia parte dos círculos românticos - que tinha na reflexão sobre a relação entre mito (mitologia), filosofia e cultura, um dos seus temas centrais, senão, o mais importante (Cf. HABERMAS, 1990, p. 89-94). Para estes autores, não obstante as divergências de fundamentação, a arte deveria ocupar uma posição privilegiada sobre as outras formas de produção humana pois ela é o local da unidade daquilo que na natureza e na história se encontra disperso. Sendo assim,

[...] é a arte e não a filosofia que guarda a chama daquela identidade absoluta que outrora se inflamara nos cultos festivos das comunidades de fé. A arte, que readquirira na forma de uma nova mitologia o seu carácter público, deixaria de ser apenas organon, passando também a meta e futuro da filosofia. (HABERMAS, 1990, p. 94-95).

Porém, se é este o problema presente a Nietzsche em NT e nos textos do mesmo período, isto não representou um condicionamento àquela tradição, pois há uma distância considerável a marcar os seus empreendimentos. Enquanto aqueles autores concediam à poesia o poder de criação da nova mitologia, Nietzsche considerava que somente a música possui tal poder, subordinando a palavra à 
música. ${ }^{7}$ Por outro lado, os românticos conceberam a criação da nova mitologia a partir daquilo que a cultura alemã "oferecia", associando o cambaleante deus grego Dionísio à figura de Cristo, considerando que, como aquele, este também evocava a simbologia da eterna recriação e da redenção da vida. Para Nietzsche, este equívoco, por demais grosseiro, demonstrava a completa ignorância dos românticos acerca da radicalidade do significado trágico da cultura grega, bem como, a falta de radicalidade do seu empreendimento pois, fundar sobre o mito - mito trágico - uma cultura como a alemã sem um procedimento crítico, destrutivo, significava simplesmente, não operar nenhuma mudança substancial. Ao vivenciar junto a Wagner um empreendimento regido pelo espírito da música, pelo qual vislumbrava a recondução do mito, da vivência trágica, ao coração da cultura alemã, Nietzsche distanciou-se das concepções estéticas românticas. ${ }^{8}$ Por outro lado, no gênio do artista Wagner, Nietzsche vislumbrou um novo estágio do espírito alemão capaz de operar, juntamente com o filósofo do conhecimento trágico, a fundação de uma cultura trágica destituída das motivações cristãs, tão caras aos românticos. ${ }^{9}$

Se a tragédia grega pereceu com o evanecer da música, somente pelo espírito da música uma cultura trágica poderia renascer. Esta tese, enunciada por Nietzsche no início do $\$ 16$ de NT, é o marco divisor da obra, na medida em que o que estava em questão até o \$ 16 era a análise do nascimento e da morte da tragédia, enquanto que após o $\$ 16$, Nietzsche se deteve na reflexão do significado da música e da sua relação com o surgimento do mito no interior de

\footnotetext{
${ }^{7}$ Neste particular, a vinculação de Nietzsche a Wagner e a Schopenhauer, permite explicitar os motivos do distanciamento de Nietzsche para com os românticos.

${ }^{8}$ Embora posteriormente reconhecesse na obra de Wagner a consumação do romantismo e da própria modernidade.

9 A partir desta questão, Nietzsche marcará o seu progressivo distanciamento de Wagner. Segundo ele, Wagner também sucumbiu aos temas e motivações cristãs, tendo sido infetado pelo cristianismo.
} 
uma cultura, presentificado no drama musical wagneriano.

Afinal, a que se deve a consideração nietzscheana da novidade e da superioridade da obra musical de Wagner? A predileção pelo compositor traduz traços de personalidade nos quais o pensador sucumbiu às afecções pessoais, ou revelam motivos de ordem teórica encontrados por Nietzsche na obra musical de Wagner? É possível responder a estas questões, mostrando que ambas motivações são preponderantes e que o aspecto pessoal da relação Nietzsche/Wagner, antes de ser um obstáculo ao tratamento do problema, constitui um poderoso móvel de engendramento da reflexão nietzscheana neste período.

O primeiro aspecto da revolução operada por Wagner na música diz respeito à composição musical. Com ele, o sistema tonal é levado à beira da dissolução ${ }^{10}$. Wagner operou a minimização da importância da fidelidade ao tom, característico das composições tonais, criando uma música sustentada pela dispersão tonal.

Porém, também verifica-se em Wagner uma profunda vinculação entre produção musical e atividade literária. Para ele, a atividade musical não se restringia à composição, vinculando-se ao domínio da discussão sobre o significado da obra de arte bem como da relação entre arte e cultura. Este aspecto particular da concepção wagneriana da obra musical chamou a atenção de Nietzsche pois, o estabelecimento do diálogo entre música e cultura, possibilitavalhe a instauração da problemática do trágico na cultura, através da atualização da temática grega.

Se à atividade musical de Wagner, juntava-se a atividade literária, esta caracterizava-se por uma profunda ligação com as questões germânicas pois, "[...] a maioria dos dramas musicais são

\footnotetext{
${ }^{10}$ Tonal é a denominação genérica (conceituação) dada ao sistema musical formado gradativamente a partir do fim da Idade Média até o século XVIII, caracterizado pela constância melódica sustentada em um determinado tom dominante - daí tonal - enquanto que a melodia gira em torno da escala do tom elegido e o ritmo produz as variações contidas no tempo e no contra-tempo do pulso. A este respeito, verificar: WISNIK, 1989, p. 111-170.
} 
baseados em lendas e mitos germânicos" KIEFER, 1993, p. 225). $\mathrm{Na}$ estrutura cênica dos seus dramas, Wagner buscava revitalizar os mitos germânicos a partir do espírito da música, objetivando apresentar aos espectadores as questões mais complexas e obscuras da existência de maneira compreensível, sem recorrer ao subterfúgio dos raciocínios complexos. Para Nietzsche, o fundamental dessa atividade consistia na revitalização do mito enquanto sustentáculo da saúde da cultura - um análogo da Grécia arcaica - e na abertura para a construção do sentido da obra de arte por meio da intuição do espectador e não da elaboração abstrata. ${ }^{11}$ Este último postulado, sustentava-se na crença de que o engendramento do mito só era possível a partir da vivência cênica do universo contraditório dos sentimentos. Neste domínio Wagner revelou uma das suas facetas mais radicais.

Antes de Wagner, a música possuía fronteiras totalmente estreitas; ela aplicava-se às condições permanentes dos homens, àquilo que os gregos denominaram Ethos e, precisamente, somente com Beethoven ela começou a encontrar a linguagem do Pathos, dos desejos apaixonados, do fenômeno dramático no interior do homem. (NIETZSCHE, 1988, p. 491).

Segundo esta caracterização, toda a música anterior a Wagner - alguma exceção seja feita a Beethoven - estava condicionada pelos ditames do Ethos, representando estados de alegria ou calma. A "proibição" da representação das paixões, do Pathos, motivava-se pela concepção estético-moral que postulava o excesso como o não ético. Operando com uma concepção estética distinta, Wagner elevou o problema da representação da paixão em um dos móveis do seu drama musical. Neste sentido, "[...] o gigantismo dos gestos, as sonoridades oceânicas, o virtuosismo embriagador, auto-afirmativo, a teatralidade

${ }^{11}$ Trata-se aqui da recusa da abstração excessiva em questões relacionadas à arte. 
oca" (KIEFER, 1993, p. 225), vislumbram perfeitamente a recusa do Ethos em favor do Pathos e o império do tema dos sentimentos como mote da obra wagneriana. Tal procedimento converteu-se em argumento auxiliar para a recusa nietzscheana das teorias que consideravam a serenidade a característica distintiva da cultura grega.

O tema da representação dos sentimentos tempestuosos no drama musical, suscitou a Wagner o difícil problema da relação entre palavra e música. $\mathrm{O}$ caráter inédito da concepção wagneriana exigia uma nova linguagem musical e uma nova expressividade da língua alemã. O primeiro aspecto do problema, Wagner resolveu-o criando uma linguagem musical que ele julgava próxima da natureza, das coisas. Para tanto, por um lado, modificou a estrutura das peças, jogando ao máximo com as possibilidades harmônicas e melódicas, destituindo a vigência do tonalismo; por outro, no que diz respeito à palavra em si,

Privilegiando o recurso da aliteração, despojando a linguagem de todos os rigores da lógica e da sintaxe que a tornam refratária ao canto e a arrastam como uma engrenagem enferrujada, confiando no caráter original e inesgotável da língua alemã, na força sonora guardada na raiz das palavras, Wagner torna a linguagem audaciosamente concisa, simplifica o encadeamento dos períodos, dá força e modulação rítmica às frases. faz uso de uma notável riqueza de palavras vigorosas e expressivas, nascidas de uma 'veia popular e proverbial', em suma, 'converte a linguagem de pensamentos em uma linguagem de sentimentos'. Além disso, para cada um de seus dramas, ele compõe uma música bem especial, ritmada pêlos versos patéticos dos personagens, onde as palavras estão envolvidas e submersas na melodia. (DIAS, 1994, p. 91) 
Este procedimento fundava-se na tentativa de fazer reviver o mito. ${ }^{12}$ Sendo uma imagem do mundo acessível através de acontecimentos, o mito não se manifesta por meio de encadeamentos abstratos, pois revela símbolos intemporais apenas captáveis de modo imediato, direto. Enquanto revelador de uma "verdade" simbólica, a revelação da verdade mítica exige uma linguagem que lhe seja própria, que respeite a sua dimensão simbólica. Ora, se o objetivo de Wagner era fazer reviver o mito e não explicá-lo, e se a linguagem usual não lhe parecia a mais adequada para a realização da empresa proposta, restavalhe a criação de uma nova linguagem que, escapando da sofisticação e do encadeamento lógico, abstrato, reconduzisse o conteúdo mítico ao seu domínio mais expressivo, o domínio simbólico. Em conseqüência, segundo Nietzsche, Wagner também foi inovador enquanto poeta. (Cf. NIETZSCHE, 1988, p. 203).

A empresa wagneriana carregou consigo os estigmas da renovação. Wagner criou uma nova estrutura musical, um novo tipo de linguagem musical, novas intensidades nas palavras e nos sons e, inevitavelmente, tudo isso exigia uma nova estrutura cênica associada a uma nova concepção de teatro e de público. A construção do teatro na cidade de Bayreuth objetivava operar uma revolução no ambiente artístico e cultural da Alemanha pois recusava a concepção do teatro como espaço de descanso das atividades árduas do trabalho semanal. Para Wagner, o teatro não era entretenimento e diversão, e sim o espaço no qual um público artista deveria exercitar-se contra a disjunção entre a vida e as instituições.

Esta concepção - endossada entusiasticamente por Nietzsche - revelava a vigência do princípio da formação (Bildung) nas teorias e práticas teatrais na Alemanha do século XIX. Embora não existisse na concepção teatral e musical de Wagner uma pedagogia da

12 Tal exercício construtivo no âmbito da língua pátria desenvolvido por Wagner, foi um dos aspectos mais valorizados por Nietzsche. Atesta tal afirmação a crítica desenvolvida por Nietzsche em NT ao tratamento abstrato da arte já desenvolvidas no primeiro item deste capítulo.

Educ. e Filos. Uberlândia, v. 23, n 45, p. 47-64, jan./jun. 2009.

60 
formação do público no sentido estrito, não se pode negar o caráter essencialmente formativo, auto-formativo do teatro na acepção wagneriana. Para ele, tratava-se de educar pelo gosto artístico e para o gosto artístico. A formação pela arte trazia consigo a proposta de uma reconstrução da cultura através de uma reeducação do espectador. Quer dizer, formar-se pela arte significava a efetivação do ideal do "público artista" concebido como um público disposto a transformar-se pela arte e que avaliava a cultura através dos princípios artísticos. Nesta concepção de formação, o teatro não substituiria os estabelecimentos de ensino, a educação formal. Tratava-se sim da instauração de um processo de crítica e de refundação das instituições sociais a partir do teatro. Se o elemento característico desta empresa formativa residia na valorização da tensão inerente à estrutura das peças, a idéia da formação para a arte encontravase plenamente contemplada nos projetos de Nietzsche e Wagner, pois o princípio artístico por eles abraçado caracterizava-se pela valorização extrema da tensão, enfim, da mudança. Ora, o elemento mais significativo do processo formativo ao qual o espectador era submetido no teatro era a vivência da tensão e a intensificação daquela vivência pelo reconhecimento da tensão e da mudança como características da própria vida. Neste sentido, embora a formação pela arte não possa ser interpretada como uma formação total do homem - pois sustentava-se na compreensão da impossibilidade do fechamento absoluto de qualquer dimensão da realidade - pode sim ser interpretada como um modelo de formação que incorporou a mudança como princípio diretor do processo formativo e que não tinha como máxima o enclausurar-se nos modelos e nos princípios da educação formal. Sendo assim, é particularmente significativo que este modelo de formação surgisse no teatro.

No prefácio de NT dirigido a Wagner, Nietzsche situou o problema da arte e do ressurgimento do mito através do drama musical wagneriano, como sendo o problema alemão por excelência, posicionando-se claramente contra a euforia causada pela vitória alemã 
na guerra franco-prussiana. No seu entender, o problema fundamental de uma cultura não seria encontrado no campo de batalha. Se o que está em questão é a reflexão sobre a criação de uma cultura estética, Bismarck, o grande idealizador da unificação política alemã, afiguravase desprezível por resumir e sacrificar a legítima preocupação com a criação de uma cultura verdadeira - regida pela arte - às questões militares. Segundo Nietzsche, somente em Wagner e na empresa de Bayreuth a máxima da justificação estética da existência poderia aceder a princípio de renascimento cultural.

Todas estas observações, permitem pôr às claras o difícil problema da efetivação desta concepção formativa do teatro. Em virtude da sua amplitude, a concepção de formação (Bildung) vinculada ao teatro wagneriano congregava um problema crônico. Este problema, percebido pelo próprio Nietzsche, dizia respeito à relação entre a crítica, a reconstrução da cultura e o fato de que o público freqüentador do teatro era formado nos valores daquela cultura que se pretendia criticar. Se a visão do espectador não fosse afetada, com o passar do tempo a radicalidade e a dimensão revolucionária daquela concepção de arte sofreria abalos significativos; pois, ou a potência da sua radicalidade não se fazia sentir suficientemente por uma incompatibilidade total entre os seus princípios e os valores do público - embora não negasse a sua radicalidade, esta incompatibilidade poria fim a pretensão de instituir uma mudança significativa da vida social pois não receberia a contrapartida necessária para a instituição dos princípios revolucionários -; ou então, mostraria que não havia radicalidade nenhuma em seus princípios pois contrariamente à crítica, a aceitação pelo público das concepções vinculadas no teatro significaria o estabelecimento de um pacto com a cultura vigente. Seguindo um juízo elaborado por Nietzsche após a inauguração da "Festspielhaus de Bayreuth", o teatro wagneriano foi o modelo, levado à completude, deste último caso. Em 1876, ao acompanhar as primeiras apresentações em Bayreuth, Nietzsche decepcionouse profundamente, pois percebeu que a proposta revolucionária de 
Wagner transformara-se em apenas mais um espetáculo para a classe burguesa alemã. Segundo ele, Wagner abandonara o entusiasmo e a radicalidade inicial, transformando-se em um alemão do "Reich". Conseqüentemente, sua concepção de teatro alterou-se. A partir de então, Wagner incorporou motivos cristãos, imperialistas e antisemitas às suas peças. Ou seja, a empresa de crítica e renovação da cultura deu lugar a um reforço da cultura alemã. Desta forma, o teatro deixara de ser o espaço de formação da cultura mediada pela arte, passando a ser um teatro cujos temas tinham a arte apenas como meio necessário para a expressão de temas não estéticos. Este foi o principal motivo para a ruptura entre ambos. Se ainda permanece em aberto a questão sobre a possibilidade formadora do teatro, resta dizer que a vinculação entre Nietzsche e Wagner não significou uma completa submissão de Nietzsche à proposta wagneriana. A concepção nietzscheana da formação, da cultura, construiu-se por uma mescla de vários elementos, dos quais, a concepção estética de Wagner era apenas mais um. Para Nietzsche, uma concepção de formação sustentada na crítica incondicional dos valores de uma cultura - no caso, a cultura alemã - deveria forjar uma perspectiva de valores distinta, sem o que, a empresa redundaria em fracasso, pois permaneceria no nível da mera repetição.

\section{Referências}

DIAS, Rosa Maria. Nietzsche e a Música. Rio de Janeiro: Imago Ed., 1994.

HABERMAS, Jürgen. O Discurso Filosófico da Modernidade. Trad. Ana Maria Bernardo (et all.). Lisboa: Publicações Dom Quixote, 1990.

KIEFER, Bruno. O romantismo na música. In: GUINSBURG, J. (Org.). O romantismo. São Paulo: Perspectiva, 1993. p. 209-237. 
NIETZSCHE, Friedrich Wilhelm. Além do Bem e do Mal. Trad. Paulo César de Souza, $2{ }^{\text {a }}$ ed. São Paulo: Companhia das Letras, 1992a.

. Ecce Homo : Como alguém se torna o que é. Trad. Paulo César de Souza. São Paulo: Companhia das Letras, 1995.

Genealogia da Moral: uma Polêmica. Trad. Paulo César de Souza. São Paulo: Companhia das Letras, 1998.

. O Nascimento da Tragédia ou Helenismo e Pessimismo. Trad. J. Guinsburg. São Paulo: Companhia das Letras, 1992b.

. Sämtliche Werke. Kritische Studienausgabe (Band I). Hersg. Giorgio Colli und Mazzino Montinari. München/Berlin/New York: Deutscher Taschebuch Verlag/Walter de Gruyter, 1988.

WISNIK, José Miguel. O som e o sentido. São Paulo: Companhia das Letras, 1989.

Data de Registro 26/03/07

Data de Aceite 20/02/08 